\title{
Seismic vulnerability of existing masonry buildings: Nonlinear parametric analysis
}

\author{
Nuno Mendes and Paulo B. Lourenço
}

\begin{abstract}
Existing masonry structures are usually associated to a high seismic vulnerability, mainly due to the properties of the materials, weak connections between floors and load-bearing walls, high mass of the masonry walls and flexibility of the floors. For these reasons, the seismic performance of existing masonry structures has received much attention in the last decades.

This study presents the parametric analysis taking into account the deviations on features of the gaioleiro buildings - Portuguese building typology. The main objective of the parametric analysis is to compare the seismic performance of the structure as a function of the variations of its properties with respect to the response of a reference model. The parametric analysis was carried out for two types of structural analysis, namely for the non-linear dynamic analysis with time integration and for the pushover analysis with distribution of forces proportional to the inertial forces of the structure. The Young's modulus of the masonry walls, Young's modulus of the timber floors, the compressive and tensile non-linear properties (strength and fracture energy) were the properties considered in both type of analysis. Additionally, in the dynamic analysis, the influences of the viscous damping and of the vertical component of the earthquake were evaluated. A pushover analysis proportional to the modal displacement of the first mode in each direction was also carried out.

The results shows that the Young's modulus of the masonry walls, the Young's modulus of the timber floors and the compressive non-linear properties are the parameters that most influence the seismic performance of this type of tall and weak existing masonry structures. Furthermore, it is concluded that that the stiffness of the floors influences significantly the strength capacity and the collapse mechanism of the numerical model. Thus, a study on the strengthening of the floors was also carried out. The increase of the thickness of the timber floors was the strengthening technique that presented the best seismic performance, in which the reduction of the out-of-plane displacements of the masonry walls is highlighted.
\end{abstract}

Key Words: Masonry, existing buildings, earthquakes, seismic performance.

Nuno Mendes

ISISE - Institute for Sustainability and Innovation in Structural Engineering

University of Minho, 4800-058 Guimarães, Portugal email: nunomendes@civil.uminho.pt

Paulo B. Lourenço

ISISE - Institute for Sustainability and Innovation in Structural Engineering

University of Minho, 4800-058 Guimarães, Portugal email: pbl@civil.uminho.pt 


\section{Introduction}

The seismic behaviour of existing masonry buildings is particularly difficult to characterize and depends on several factors, such as the material properties, the geometry, the foundations, the connections between walls and floors, the connections between walls and roof, the stiffness of the horizontal diaphragms or the building condition. Furthermore, "non-structural" elements (partition walls) and their connection to the load-bearing walls can also contribute to the performance of these buildings.

Masonry is a composite material that consists of units and mortar, which had been used for construction of housing and many important monuments around the world. Units can be bricks, blocks, ashlars, irregular stones and others. Mortar can be clay, bitumen, chalk, lime/cement based mortar, glue or other. The huge number of possible combinations generated by the geometry, nature and arrangement of units as well as the characteristics of the joints raises doubts about the accuracy of the term masonry to identify a single structural material.

The strength of masonry depends on the unit and mortar properties as well as on the construction technique. As an example, the compressive strength of stone units may range from values such as $5 \mathrm{MPa}$ (low quality limestone), and even less for tuff, to over $130 \mathrm{MPa}$ (good quality limestone), and even more for granite or marble. The strength of the mortar also presents large variations and depends on the proportion of its components (cement, lime, sand, soil and water) used in the mix [1]. The compressive strength of the mortar of existing masonry buildings can be about 1.5-3.5 MPa [2,3], even if weaker and stronger mortars can be found. Furthermore, the strength and failure modes of masonry are dependent on the loading direction and combination of the loads [4]. Nevertheless, the mechanical behaviour of different types of masonry has some common features: high specific mass, low tensile strength, low to moderate shear strength and low ductility. The specific mass of stone masonry can range between $1700 \mathrm{~kg} / \mathrm{m}^{3}$ to $2200 \mathrm{~kg} / \mathrm{m}^{3}$ [5].

The characteristics of masonry make it a material mainly suitable for structural elements subjected to compressive stresses caused by vertical static loads, such as walls, arches, vaults and columns subject to the self-weight. Masonry properties have a direct influence on the seismic performance of unreinforced masonry buildings and massive damages have been observed in strong seismic events. The inertial forces induce tensile and shear stresses, which may lead to the failure of masonry elements and, consequently, to local or global collapse of the building. More information on the mechanical behaviour of the masonry is given in $[1,4,6]$.

The geometrical regularity in plan and in elevation as well as the structural simplicity (well distributed of mass and stiffness) improve the seismic performance of masonry structures, preventing local damage and decreasing torsional effects. These criteria, together with requirements for material properties in terms of strength and robustness, and rules for design and detailing are present in modern codes $[7,8,9]$, aiming at obtaining a good seismic performance of masonry 
buildings in terms of strength capacity and adequate collapse mechanisms. However, existing masonry buildings often present geometric and material properties, which may lead to brittle or non-proportionated collapse mechanisms. In general, the damage observed in unreinforced masonry buildings due to the seismic action are cracks between walls and floors, cracks at the corners and at wall intersections, out-of-plane collapse of the external walls, cracks in spandrels beams and/or parapets, diagonal cracks in structural walls, partial disintegration or collapse of structural walls and partial or complete collapse of the buildings [6]. For more information about the damage on unreinforced masonry buildings, see e.g. [10,11].

This study presents a dynamic and static nonlinear parametric analysis, taking into account the main variations on the features of the existing masonry buildings. The main objective of the parametric analysis is to compare the response of the structure as a function of the change of its properties with respect to the response of a reference numerical model. The reference mode was calibrated based on the results obtained from the shaking table tests. The parametric analysis was carried out using nonlinear dynamic analysis with time integration and pushover analysis proportional with distribution of forces proportional to the mass. The comparison of the response of structure is mainly based on the maximum load capacity and type of damage. Finally, a study on strengthening of the floors was carried out.

\section{Seismic performance of existing masonry buildings}

Although the seismic performance of unreinforced masonry buildings depends on several aspects, only the seismic behaviour of the masonry walls and of the floors are discussed here.

The in-plane behaviour of masonry walls depends on the geometry of piers, spandrels and openings. Three configurations of walls can be distinguished. Cantilever walls connected by floors (Figure 1a), which even if rigid in their plane are flexible in the orthogonal direction and do not transfer the moments resulting from the bending of the walls. This configuration is assumed as the best masonry structural model for a ductile response, as the walls act as props and the maximum moments and energy dissipation occurs at the base of the walls. The coupled walls with pier hinging (Figure 1b) present piers weaker than the spandrels and the damage tend to initiate at the piers. In general, the piers at the lowest storey will either fail due to the diagonal compression (shear failure) or by the crushing of masonry, requiring high ductility at this floor level. However, the shear failure of the piers is not favourable to the ductility and energy dissipation of the structure. The coupled walls with spandrel hinging (Figure 1c) occur when spandrels are weaker than the piers. The spandrels behave as coupling beams, connecting the walls and transferring bending moments. Damage occurs at both elements and energy dissipation is distributed over the entire structure. The behaviour of coupled walls with spandrel hinging is the most desirable wall configuration [1,6]. 


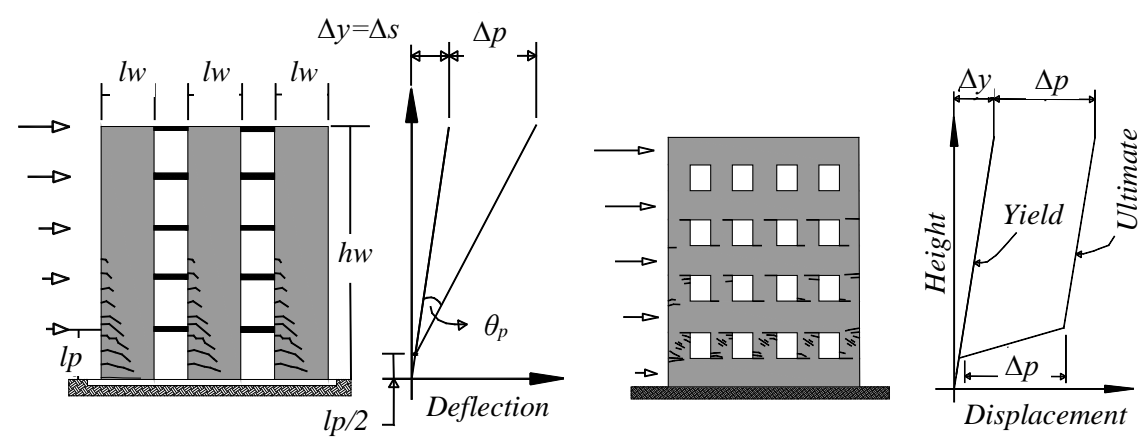

(a) (b)

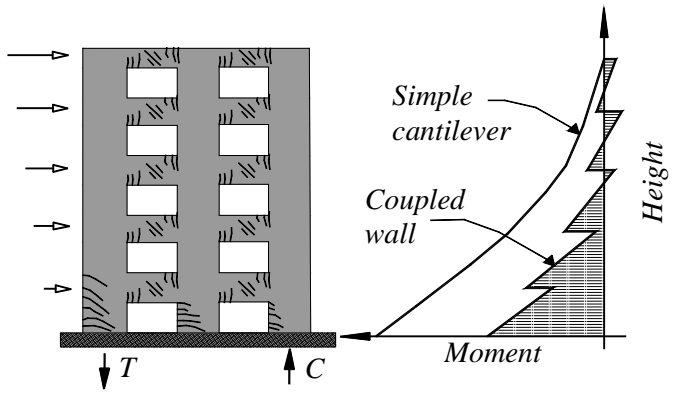

(c)

Fig. 1 In-plane structural models of masonry walls: (a) cantilever walls connected by flexible floors; (b) coupled walls with pier hinging; (c) coupled walls with spandrel hinging. (adapted from [1])

In what concerns the seismic behaviour of piers, the typical in-plane collapse mechanisms (Figure 2) [1,12,14]:

- Rocking induced by bending, which causes horizontal cracks at the top and at the bottom of the pier. The failure of the pier occurs by overturning of the wall. The failure by in-plane overturning, which occurs rarely, is associated to very slender and slightly loaded piers;

- Sliding associated with horizontal forces at the piers that are larger than the shear strength of the bed joints (low vertical load and low friction coefficient), which is characterized by single full pier width horizontal cracks;

- Diagonal tension, in which the principal tensile stress caused by the seismic action exceeds the strength of masonry and diagonal cracks arise. The cracks can propagate along the bed and head joints or go through the units, depending on the strength of the mortar, mortarunit interface and unit;

- Toe crushing, which can appear in combination with rocking or diagonal tension. The toes of the piers are usually zones of high com- 
pressive stresses and when the principal compressive stress caused by the seismic action exceeds the strength of the masonry, compressive failure (crushing) can occur.



Rocking



Sliding

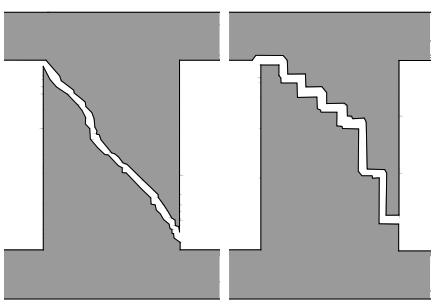

Diagonal tension

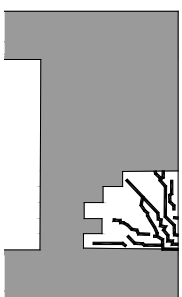

Toe crushing

Fig. 2 In-plane collapse mechanisms of the piers (adapted from [14]).

The behaviour of spandrels is similar to the behaviour of piers. However, two aspects have to be taken into account: (a) the axis of the spandrel is horizontal and not vertical as in the piers; (b) the normal stress existing in the spandrels, caused by vertical loads, is much lower than the one in the piers. The first aspect is important for regular masonry, due to the orthotropic behaviour, while the behaviour of irregular masonry is more independent from the load direction. The second aspect has consequences in all types of masonry, as the normal stress has a strong influence on strength. Figure 3a presents the in-plane behaviour of spandrels subjected to a seismic action, in which shear stresses occur and can lead to them to collapse (Figure 3b). In masonry buildings with elements that prevent such collapse mechanisms (Figure 3c), diagonal compression occurs and these elements increases the bending strength of the spandrels. Under these conditions, the spandrels present two possible collapse mechanisms [15,16]:

- Collapse due to high compression of diagonal struts (similar to the collapse of piers subjected to combined axial and bending forces);

- Collapse due to diagonal tension (shear failure).



(a)

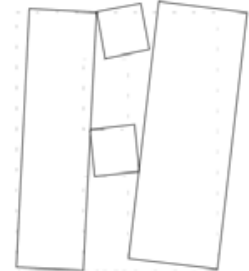

(b)



(c)

Fig. 3 In-plane behaviour of spandrels [17]: (a) sprandrel subjeted to the seismic action: (b) unreinforced spandrel; (c) reinforced spandrel. 
FEMA 306 [18] also presents the typical damage and collapse mechanisms of the in-plane behavior of unreinforced masonry walls subjected to the seismic action (Figure 4). The walls without openings (URM1) can present rocking, toe crushing, sliding and diagonal tension. Furthermore, these walls can also present sliding at the wall/foundation interface and foundation rocking. The collapse mechanisms of the walls with openings, i.e. at the spandrels (URM3) or at the piers (URM2 and URM4), is defined by their geometry. Finally, the unusual collapse of the "joints", caused by diagonal tension, is also possible (URM5).

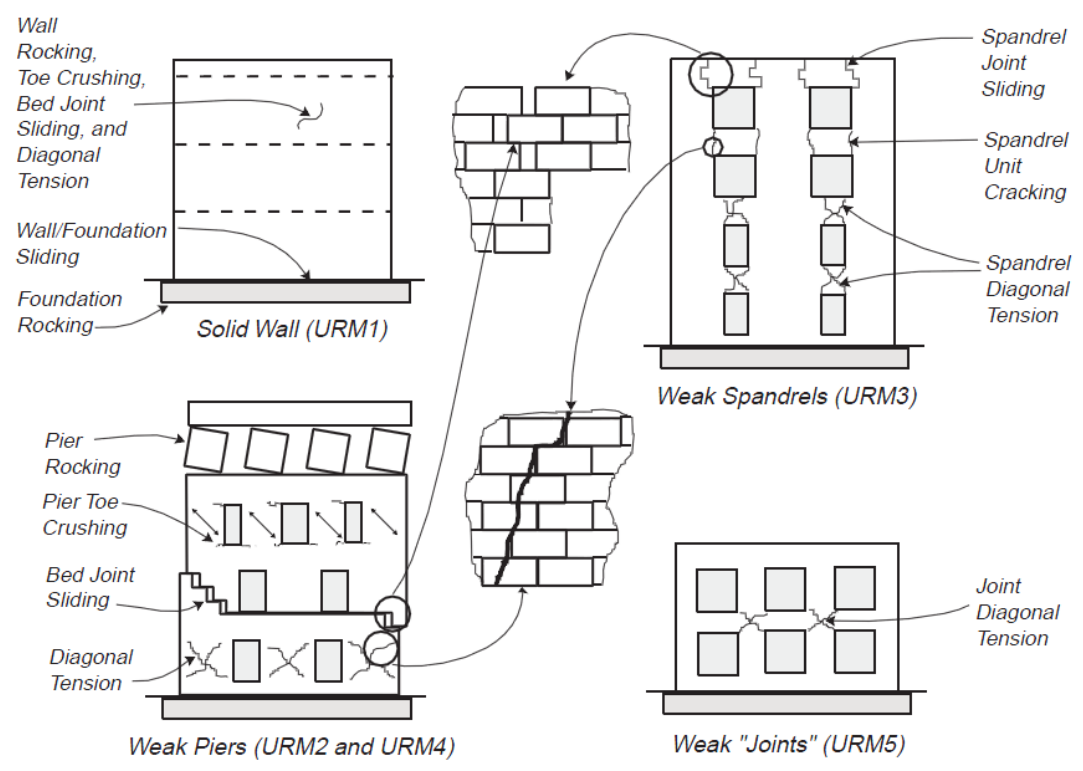

Fig. 4 In-plane behaviour of masonry walls [18].

The out-of-plane behaviour of unreinforced walls is rather complex and depends on the connection between walls and floors/roof, the connection between transverse and longitudinal walls, and the in-plane stiffness of the floors. When the floors are rigid and are adequately connected, masonry walls have local effects, as shown in Figure 5. On the other hand, when the floors are flexible or the connection between the walls and the floors is weak, the walls exhibit a global behaviour (independent of the floor levels) with collapses involving one or more floors and, consequently, have lower stiffness and strength [19].

Figure 6 presents examples of the in-plane damage, namely the shear failure of piers and spandrels, in which diagonal cracks are observed. Figure 7 presents examples of out-of-plane collapse of masonry walls, with the collapse of masonry walls versus successful strengthening with ties (Figure 7b).

Diaphragms distribute the inertial forces to the vertical resisting elements. This distribution depends on the in-plane stiffness of the diaphragms and on the con- 
nection between walls and diaphragms. In contrast to a rigid diaphragm, in which the distribution among the vertical elements is affected only by the location and lateral stiffness of these structural elements, a flexible diaphragm (timber floors) usually exhibits significant bending and shear deformations under horizontal loads, influencing the distribution of the load among the elements of the structure. Therefore, the flexibility of the floor diaphragms and of the connections between these and the masonry walls plays an important role in the global and local response of masonry buildings under seismic load.



Fig. 5 Out-of-plane behaviour of the walls of masonry buildings with rigid floors (adapted from [6])

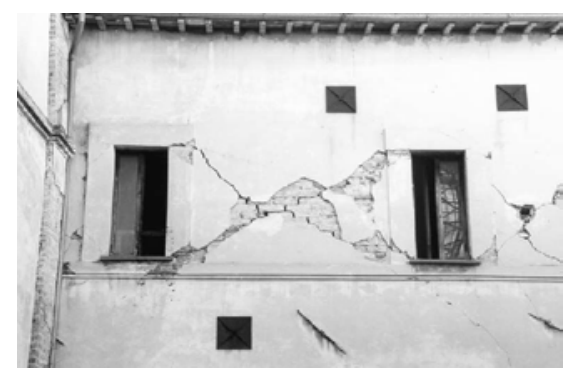

(a)



(b)

Fig. 6 Examples of shear failure of: (a) piers [20]; (b) spandrels [21].

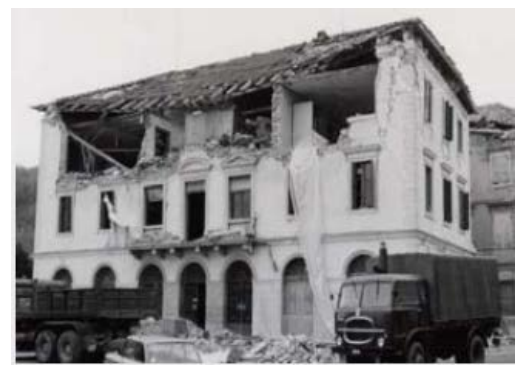

(a)

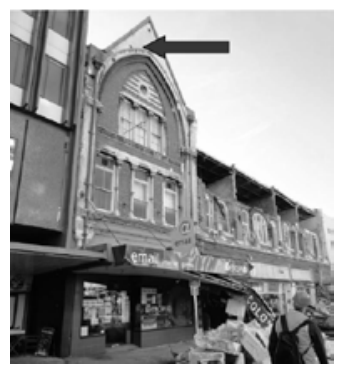

(b)

Fig. 7 Examples of out-of-plane collapse mechanism: (a) wall of the top floor [22]; (b) parapet and wall collapse and successful strengthening with ties (arrow) [23]. 
Research conducted on flexible diaphragms, e.g. [14, 24-28], showed that flexible diaphragms lead to the following behaviour:

- The overall stiffness of the floors (Figure 8), which controls the outof-plane behaviour of the masonry walls, is a combination of the inplane stiffness of the diaphragm $\left(k_{e q, d}\right)$ and the stiffness of the connections between floors and walls $\left(k_{c}\right)$. Thus, the total deformation of the floors is given by the sum of the deformations of the diaphragm and connections. When the connections are rigid $\left(k_{c}=\infty\right)$ the overall deformation is only a function of the internal stiffness of the diaphragm. On the other hand, when the diaphragms are rigid $\left(k_{e q, d}=\infty\right)$, the stiffness of the connections is taken into account. The equivalent stiffness of the floors $\left(k_{e q, d+c}\right)$, which should be used in the assessment, design and strengthening analyses, is given by the combination of both contributions $\left(1 / k_{e q, d+c}=1 / k_{e q, d}+1 / k_{c}\right)$ [24];

- The flexible diaphragms have large deformation capacity, high strength and low mass. The earthquakes show that the failure of flexible diaphragms itself is rare. In general, the failure mechanisms of flexible diaphragms are related to the lack of connections or weak connections between the masonry walls and diaphragms. Furthermore, the masonry walls vibrate in the out-of-plane direction under seismic load and tend to separate from the diaphragms, meaning that the diaphragm may slip off its supports and collapse if the diaphragm is not suitably connected to the walls [26];

- Strong diaphragms present amplifications of up 3 or 4 times the input acceleration, velocities and displacements in the elastic range [25] (citing $[29,30]$ ). On the other hand, flexible diaphragms have a highly non-linear hysteretic behaviour for large peak ground accelerations, which is favourable to reduce the diaphragm's accelerations and velocities at mid-span [30];

- Strengthening of the horizontal diaphragms is a natural solution for a better performance, even if an increase of the in-plane stiffness per se is not enough to improve the global response of the building. The seismic performance of the unreinforced masonry buildings also depends of the stiffness and strength of the connections between floors and walls [14].

For more information on the behaviour of masonry structures without box behaviour see e.g. [31-33]. 
Actual behaviour
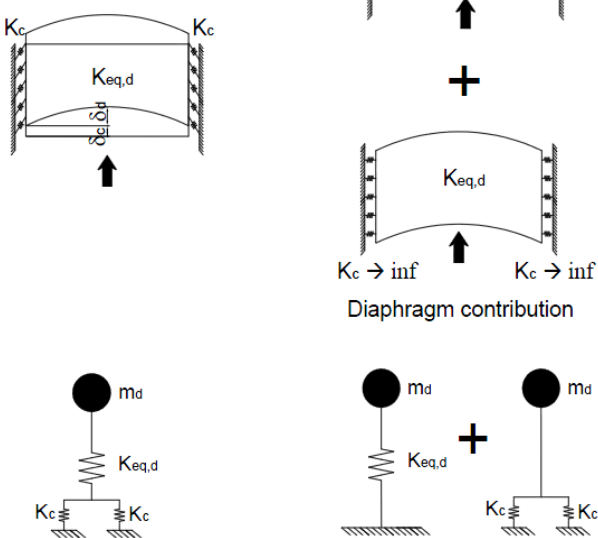

Equivalent behaviour
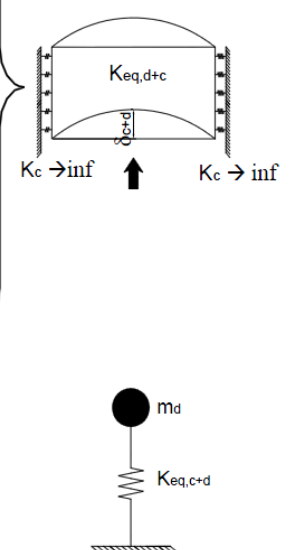

Fig. 8 Schematic contributions of connections and diaphragm stiffness to the overall floor stiffness [24].

\section{Preparation of the reference numerical model}

The numerical model is representative of a Portuguese masonry building typology - gaioleiro buildings [34] and is based on a mock-up tested at 1:3 reduced scale in the 3D shaking table of the National Laboratory for Civil Engineering (LNEC) in Lisbon [35]. The mock-up has four floors, two façades with openings, two gable walls without openings, and timber floors. The timber floors are made of mediumdensity fibreboard (MDF) panels, with thickness equal to $0.012 \mathrm{~m}$, connected to a set of timber joists oriented in the direction of the shortest span and keeping a joint of about $1 \mathrm{~mm}$ for separating the panels, aiming at simulating flexible floors.

First, a reduced numerical model was prepared and calibrated with respect to the frequencies and mode shapes obtained from the dynamic identification tests. Furthermore, the non-linear dynamic response of the reduced model (accelerations, displacements and crack patterns) was validated with respect to the experimental response obtained from the seismic tests. The results of the modal updating considered the first five modes, show that numerical model presents an average error equal to $3.6 \%$. In what concerns the mode shapes and the non-linear dynamic behaviour, the results show that the correlation between the experimental and numerical responses is good in the transversal direction and acceptable in the longitudinal direction. 
Subsequently, a numerical model was prepared at real scale (reference numerical model), using the Finite Element Method (FEM) and the non-linear analysis software DIANA [36], in which quadratic shell elements with eight nodes (CQ40S) were used for simulating the masonry walls and beam elements with three nodes (CL18B) were used for simulating the timber joists (Figure 9a). All the finite elements are based on the theories of Mindlin and Reissner, in which the shear deformation is taken into account $[37,38]$. In the modelling of the floors, shell elements were used aiming at simulating the in-plane deformability (Figure $8 b)$. The thickness of the masonry walls and of the MDF panels is equal to 0.510 $\mathrm{m}$ and $0.036 \mathrm{~m}$, respectively, and the dimensions of the cross section of the timber joists are equal to $0.300 \times 0.225 \mathrm{~m}^{2}$ (width and height), with spacing of $1.05 \mathrm{~m}$. In plan, the numerical model has $9.45 \times 12.45 \mathrm{~m}^{2}$ and the interstory height is equal to $3.60 \mathrm{~m}$. The translation and rotation degrees of freedom at the base were restrained. In what concerns the connections, tyings providing equal translation of degrees of freedom between walls and floors were assumed. The numerical model involves 5,816 elements (1,080 beam elements and 4,736 shell elements) with 15,176 nodes, resulting in 75,880 degrees of freedom.



(a)

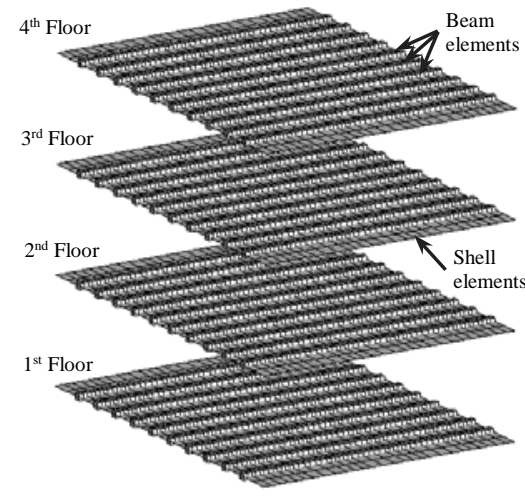

(b)

Fig. 9 Numerical model: (a) general view; (b) detail of the floors

The selection of the masonry constitutive model was based on a compromise between accuracy of the results and computation time. The Total Strain Fixed Crack Model [36] assumes smeared cracks based on total strains and was selected due to its robustness and simplicity. In this model, the crack directions are fixed after the onset of cracking. The non-linear behaviour of the masonry was considered assuming exponential softening for the tensile behaviour and parabolic hardening followed by softening for the compressive behaviour. The shear behaviour was simulated by a linear relationship between stress and strains, in which the shear stiffness is reduced after cracking according to the following equation: 


$$
G^{c r}=\beta G
$$

where $G^{c r}$ is the shear modulus after cracking, $G$ is the elastic shear modulus and $\beta$ is the shear retention factor (ranging from zero to one).

The crack bandwidth $h$ for the shell elements was estimated as function of the area of the element $A$, making the analysis results independent of the size of the finite element mesh:

$$
h=\sqrt{A}
$$

Tables 1 and 2 present the linear and non-linear material properties of the reference numerical model, respectively. It is noted that the updated Young's modulus of the MDF panels presents a very low value $(0.16 \mathrm{GPa})$, simulating the flexible timber floors with joints. Furthermore, this low value can also include indirectly the effect of the connection between walls and floors, since the connections of the mock-up could allow some sliding and the calibrated numerical model considers that sliding at the connections cannot occur. These have been obtained from modal updating of the experimental shaking table test, experimental data and recommendations, see [35] for details.

\begin{tabular}{|c|c|c|c|}
\hline & $\begin{array}{c}\text { Young's modulus } \\
\text { (GPa) }\end{array}$ & $\begin{array}{c}\text { Specific mass } \\
\left(\mathrm{kg} / \mathrm{m}^{3}\right)\end{array}$ & $\begin{array}{c}\text { Poisson } \\
\text { ratio }\end{array}$ \\
\hline Masonry walls & 1.00 & 2160 & 0.2 \\
\hline MDF panels & 0.16 & 760 & 0.3 \\
\hline Timber joists & 12.00 & 580 & 0.3 \\
\hline
\end{tabular}

Table 1 Linear material properties for the reference model.

\begin{tabular}{|c|c|c|c|c|}
\hline & $\begin{array}{c}\text { Compressive } \\
\text { strength } \\
f_{c}(\mathrm{MPa})\end{array}$ & $\begin{array}{c}\text { Compressive } \\
\text { fracture energy } \\
G_{c}(\mathrm{~N} / \mathrm{mm})\end{array}$ & $\begin{array}{r}\text { Tensile } \\
\text { strength } \\
f_{t}(\mathrm{MPa})\end{array}$ & $\begin{array}{c}\text { Mode I- tensile } \\
\text { fracture energy } \\
G_{t}(\mathrm{~N} / \mathrm{mm})\end{array}$ \\
\hline Masonry walls & 1.00 & 1.60 & 0.10 & 0.05 \\
\hline
\end{tabular}

Table 2 Non-linear material properties of the masonry walls for the reference model.

In what concerns damping for the non-linear dynamic analysis, the $C$ viscous damping (proportional to the velocity) of Rayleigh was adopted, which is a linear combination between the mass and stiffness matrix in the form [39]:

$$
\underline{C}=\alpha \underline{M}+\beta \underline{K}
$$

where $\alpha$ and $\beta$ are the coefficients that weigh the contribution of the mass $M$ and $K$ matrices, respectively. The values for $\alpha(0.49325)$ and $\beta(0.00157)$ were determined through the damping ratios identified in the dynamic identification tests 
carried out at LNEC and after converting them to real scale [35]. The $\alpha$ and $\beta$ values correspond to damping ratios equal to $3.20 \%$ and $3.39 \%$ for the first $(1.64 \mathrm{~Hz})$ and second $(5.42 \mathrm{~Hz})$ transversal modes, respectively.

The reference numerical model represents an isolated building. However, in the urban areas the gaioleiro buildings are usually semi-detached and belong to a block of buildings. Although it is not an objective of this work, pounding can be taken in account when the adjacent buildings present different heights or the separation distance is not large enough to accommodate the displacements [40,41]. It is noted the block effect is usually beneficial and provides higher strength of the building, as shown in [42].

\section{Seismic performance of the reference numerical model}

Non-linear dynamic analyses with time integration and pushover analyses with distribution of forces proportional to the mass were carried out. In the dynamic analysis, two artificial accelerograms were applied in two uncorrelated orthogonal directions (Earthquake 100\%). The accelerograms were generated based on stochastic methods and techniques of finite fault modelling, with parameters adequate for Portugal [43] and duration equal to $30 \mathrm{~s}$ (intense phase). The response spectrum of the accelerograms is compatible with the type 1 design response spectrum defined by Eurocode 8 [7] and Portuguese National Annex for Lisbon $\left(P G A=1.5 \mathrm{~m} / \mathrm{s}^{2}\right)$, with a damping ratio equal to $5 \%$ and a type A soil (rock, $S=1$ ).

The pushover analysis is a non-linear static analysis that aims at simulating the structural response during an earthquake, through application of incremental horizontal forces or displacements until collapse. The response of the structure is given by the so-called capacity curve, which represents the value of the base shear or seismic coefficient $\alpha_{b}$ (Eq. (4)) versus the displacement at a control point (usually at the top of the structure).

$$
\alpha_{b}=\frac{\sum \text { Horizontal forces at the base }}{\text { Self }- \text { weight of the structure }}
$$

In the non-linear dynamic analysis with Earthquake $100 \%$, the maximum seismic coefficient at the base is equal to 0.10 and 0.25 in the transversal and longitudinal direction, respectively (Figure 10). According to the pushover analyses, the force based capacity reaches its limit in the transversal direction $\left(\alpha_{b}=0.10\right)$. However, in the longitudinal direction the seismic coefficient obtained from the nonlinear dynamic analysis $\left(\alpha_{b}=0.25\right)$ is significantly lower than the force based capacity obtained from the pushover analysis $\left(\alpha_{b}=0.46\right)$. Furthermore, in this nonlinear dynamic analysis the displacement is significantly lower than the value ob- 
tained from the pushover analysis. As an example, in the transversal direction the maximum displacement at the top obtained from the non-linear dynamic analysis (Earthquake 100\%) and from the pushover analysis is about $4.4 \mathrm{~cm}$ and $20.0 \mathrm{~cm}$, respectively. Thus, the seismic action was increased and a non-linear dynamic analysis with Earthquake $300 \%\left(P G A=4.5 \mathrm{~m} / \mathrm{s}^{2}\right)$ was carried out, aiming at exploring the deformation capacity of the structure and obtaining severe damage that allows identifying clearly the collapse mechanism. In the non-linear dynamic analysis of the Earthquake $300 \%$ (Figure 10), the force based capacity is close to the one obtained from the pushover analyses. In terms of deformation, in the transversal direction the non-linear dynamic analysis of the Earthquake 300\% presents similar maximum displacement at the top. However, in the longitudinal direction the analyses present significant differences in terms of maximum displacement.

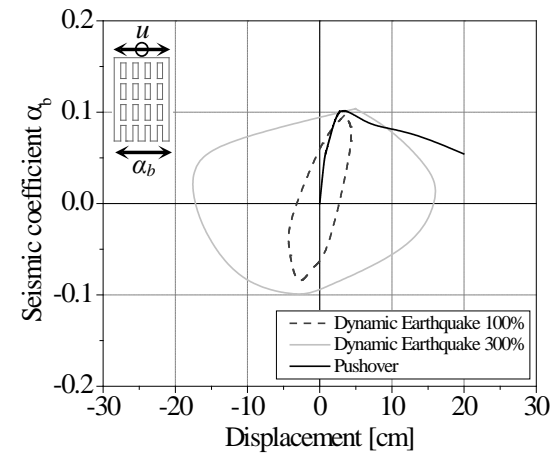

(a)

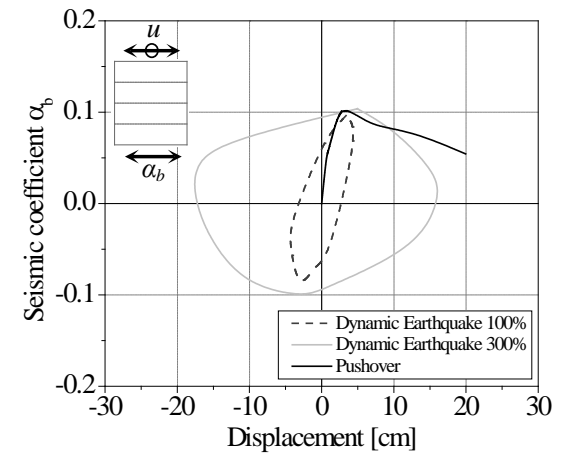

(b)

Fig. 10 Envelope of the response obtained from the non-linear dynamic analysis with time integration and capacity curve obtained from the pushover analysis of the reference model in the: (a) transversal direction; (b) longitudinal direction.

Figure 11a presents the distribution of the maximum principal tensile strains, which is an indicator of cracking, for the non-linear dynamic analysis of the Earthquake $100 \%$. It is observed that damage concentrates at the spandrels, due to the diagonal cracking, and at the piers of the top floor, due to in-plane rocking and out-of-plane bending. The gable walls do not present significant damage. In the Earthquake 300\% (Figure 11b) the structure presents severe damage, with several spandrels fully damaged and piers at the top floor presenting significant cracks due to in-plane rocking and out-of-plane bending. Furthermore, the piers of the first floor also present severe damage, due to the failure of the spandrels and do not adequately restrict the relative displacements of the piers, leading to damage mainly due to in-plane forces. The gables walls also present damage, with shear cracks, originating at the floor levels and progressing through the walls, and a vertical cracks at the top of the building, dividing the building in two. Furthermore, important local damage at the base and at the connections between the gable walls and the joists of the first floor is observed, due to impact between joists and walls. 


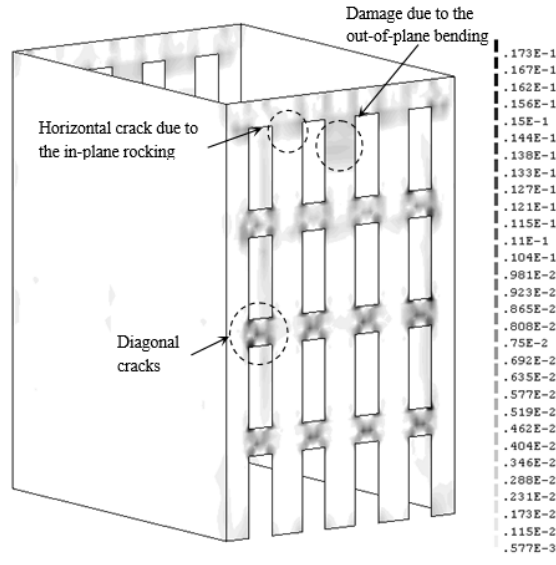

(a)

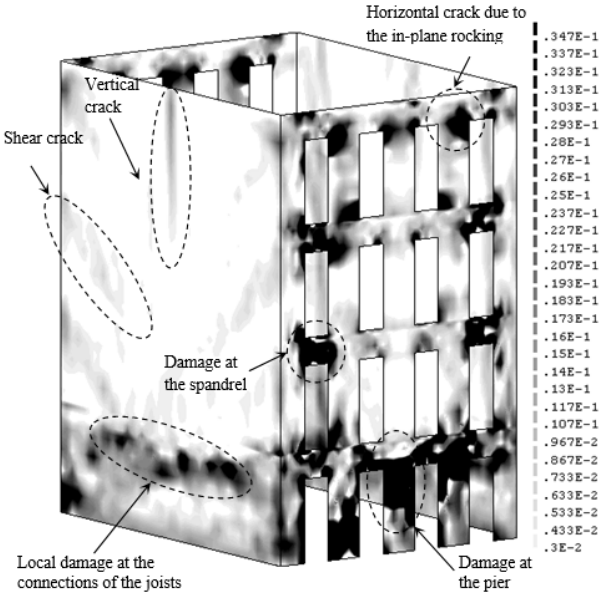

(b)

Fig. 11 Maximum tensile principal strains at the external surface of the non-linear dynamic analyses of the reference model: (a) Earthquake 100\%; (b) Earthquake 300\%.

Figure 12 presents the maximum principal strains obtained in the pushover analysis in the transversal and longitudinal direction. The transversal damage (Figure 12a) is partly in agreement to the one observed in the non-linear dynamic analysis caused by the in-plane forces (Figure 11b), mainly with damage concentration at the piers and horizontal cracks at the piers of the top floor, even if with important local differences (damage is not uniform in the dynamic analysis). The piers of the first floor and the base also present damage, but less severe in comparison to the damage observed in the non-linear dynamic analysis. In the pushover analysis in the longitudinal direction (Figure 12b) the piers of the top floor do not presents significant damage caused by the out-of-plane bending as observed in the non-linear dynamic analyses (Figure 11). The damage concentrates mainly in the gable walls, with two vertical shear cracks that have origin at the floor levels and progress to the central part of the base, and one vertical crack. According to the pushover analysis, the numerical model presents a typical collapse mechanism, in which the facades collapse with the vertical cracks occurring at the top floors of the gable walls (near to first joist of the timber floors) and at the corner of the first floor. The MDF panels are rather flexible and are not able to transfer the inertial forces of the facades to the gables, resulting in out-of-plane collapse of the facades. This collapse mechanism is not observed in the non-linear dynamic analysis, even if the maximum capacity in the longitudinal direction was also found for the Earthquake $300 \%$.

These conclusions are in agreement with different simulations made for masonry buildings without box behaviour [31], where it is advocated that, in general, the capacity and failure mode of pushover analysis for these buildings is not in agreement with experimental testing and time history analysis. 


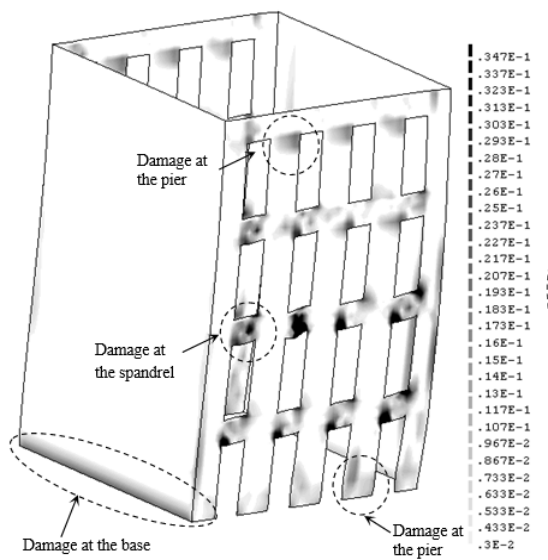

(a)

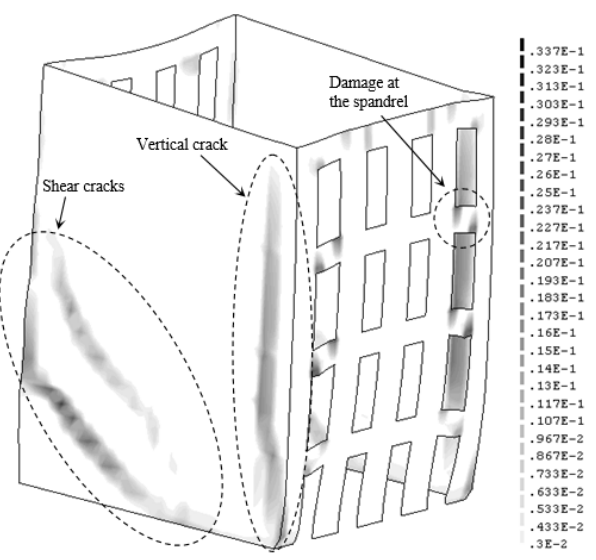

(b)

Fig. 12 Maximum tensile principal strains at the external surface of the pushover analysis of the reference model in the: (a) transversal direction; (b) longitudinal direction.

\section{Non-linear dynamic parametric analysis}

Non-linear analysis involves several parameters that can influence the response to some extent and, consequently, can also influence the conclusions about the seismic performance of existing masonry structures. Thus, a parametric analysis was carried out, by changing the value of the different parameters with respect to the reference model, taking into account the dispersion in the features of the gaioleiro building typology. The parameters considered (Table 3) are the stiffness of the masonry walls, the stiffness of the floors, the non-linear properties of the masonry in compression and tension, and the damping ratio. The reference parameters were divided and multiplied by 2, which is considered a rather large variation, with the exception of the damping ratio and the stiffness of the floors. For the damping ratio, round values considered in the code are adopted (2\% and $5 \%$ ). The stiffness of the floors can vary to great extent, due to the material adopted and the efficiency of the connections, and the reference values were divided and multiplied by 10 . Furthermore, the influence in the response of the vertical component of the earthquake was also studied. It is noted that instead of multiplying or dividing reference values by a fixed coefficient, it would be possible to consider the reference values as median values of a lognormal distribution, so adding or subtracting a similar value would allow to obtain compatible confidence levels. This would possibly provide a too narrow interval for variable parameters such as the fracture energy or the stiffness of the floors, and requires further consideration. Next, the main results of the non-linear dynamic parametric analysis (Earthquake 300\%) are presented. 
Table 3 Parameters considered in the dynamic parametric analysis.

\begin{tabular}{|c|c|c|c|}
\hline & Lower value & Reference value & Upper value \\
\hline Young's modulus of the walls & $0.5 \mathrm{x} E_{\text {walls,ref }}$ & $E_{\text {walls }, \text { ref }}=1.00 \mathrm{GPa}$ & $2.0 \mathrm{x} E_{\text {walls,ref }}$ \\
\hline Young's modulus of the floors & $0.1 \times E_{\text {floors }, \text { ref }}$ & $E_{\text {floors, ref }}=0.16 \mathrm{GPa}$ & $10 x E_{\text {floors, ref }}$ \\
\hline Compressive strength & $0.5 x f_{c, r e f}$ & $f_{c, \text { ref }}=1.00 \mathrm{MPa}$ & $2.0 \times f_{c, r e f}$ \\
\hline Compressive fracture energy & $0.5 x G_{c, r e f}$ & $G_{c, r e f}=1.00 \mathrm{~N} / \mathrm{mm}$ & $2.0 \times G_{c, r e f}$ \\
\hline Tensile strength & $0.5 x f_{t, r e f}$ & $f_{t, \text { ref }}=0.10 \mathrm{MPa}$ & $2.0 \mathrm{x} f_{t, r e f}$ \\
\hline Tensile fracture energy & $0.5 \mathrm{x} G_{t, \text { ref }}$ & $G_{t, r e f}=0.05 \mathrm{~N} / \mathrm{mm}$ & $2.0 \mathrm{x} G_{t, r e f}$ \\
\hline Damping ratio & $\zeta_{\text {Lower }}=2.0 \%{ }^{*}$ & $\zeta_{\text {ref }}=3.3 \%^{*}$ & $\zeta_{\text {Upper }}=5.0 \%^{*}$ \\
\hline Vertical earthquake & \multicolumn{3}{|c|}{ Vertical component of the earthquake } \\
\hline
\end{tabular}

The parametric analysis shows that the Young's modulus of the masonry walls, the Young's modulus of the timber floors and the compressive non-linear properties are the parameters that most influence the seismic performance of this type of structures. The maximum seismic coefficient varies about $50 \%$ with respect to the reference value when the Young's modulus of the masonry walls is changed. The stiffness of the floors has also an important role in the seismic performance of the structure. The numerical model with very flexible floor presents the typical out-ofplane collapse of the gable walls and damage at the corners. When the stiffness of the floors is increased the damage concentrates at the facades, mainly associated to in-plane forces (Figure 13).

It is expected that the variation of compressive non-linear properties has limited influence in the response of masonry structures, but here a significant influence in the strength capacity of the structure has been found (Figure 14). This is due to the low reference value of the compressive strength and the type of failure mode obtained, given the considerable height of the buildings. It should be noted that the lower limit of the compressive strength is quite low (0.50 MPa) and it is representative of a masonry very poor. According to PIET-70 [44] and the Italian code [45], the values for compressive strength of rubble masonry are in the range of 0.6-1.2 MPa. This is confirmed by flat jacks tests carried out in Lisbon [46]. Sometimes, this type of buildings go up to 5 and 6 storeys, meaning that the strength reduction is realistic. Furthermore, it is noted that the maximum compressive stress due to the self-weight is about $30 \%$ of the compressive strength, which would seem reasonable for the stability against vertical loading.

The response exhibited small variations when the tensile properties were changed. The limits considered for the material properties correspond to a common feature of masonry - low tensile strength and a quasi-brittle behaviour, meaning that the non-linear tensile properties do not to affect significantly the response under high seismic amplitudes.

The response of the structure in the transversal direction does not change significantly decreasing the ratio damping of about $1 \%\left(\zeta_{\text {Lower }}=2.0 \%\right)$. The maximum variation of the response in the longitudinal direction with $\zeta_{\text {Lower }}=2.0 \%$ is equal to $-8 \%$ (displacement at the top). In the transversal direction with $\zeta_{\text {Upper }}=5.0 \%$ the 
maximum seismic coefficient increases about $10 \%$ and the maximum displacement at the top decreases about $17 \%$. In the longitudinal direction the response $\left(\zeta_{\text {Upper }}=5.0 \%\right.$ ) presents a variation of about $20 \%$ for both parameters. The numerical model with $\zeta_{\text {Lower }}=2.0 \%$ presents serious damage at the spandrels, piers at the top floor and at the base, and at the first floor of the gable walls. On the other hand, when increasing the damping $\left(\zeta_{\text {Upper }}=5.0 \%\right)$ the numerical model presents, as expected, a damage reduction. Still, these changes in response are reasonable for engineering applications.

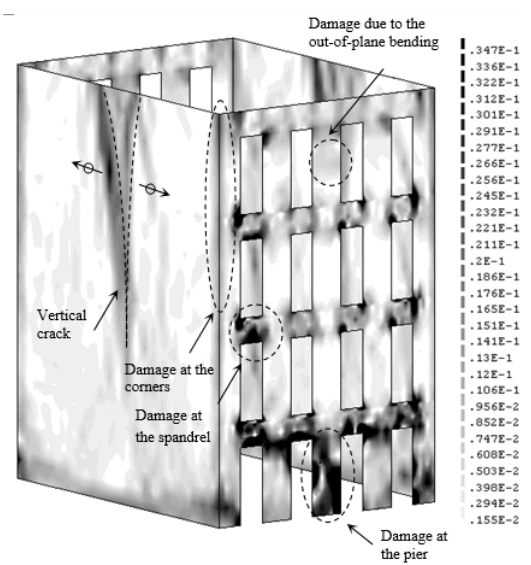

(a)

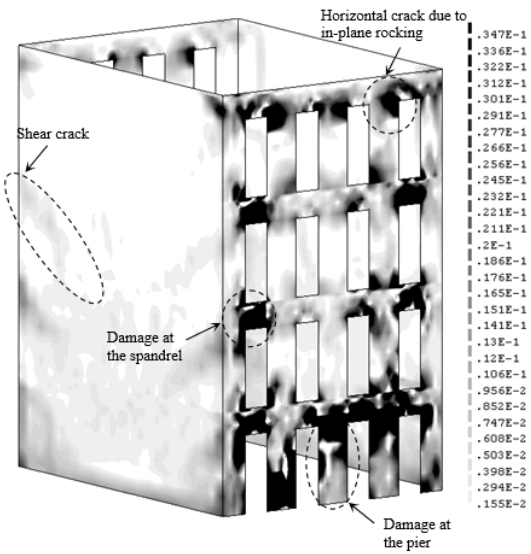

(b)

Fig. 13 Maximum tensile principal strains at the external surface, obtained from the dynamic analysis, varying the Young's modulus of the floors: (a) $0.1 \times E_{\text {floors, ref }}$; (b) $10 \mathrm{xE} E_{\text {floors, ref. }}$

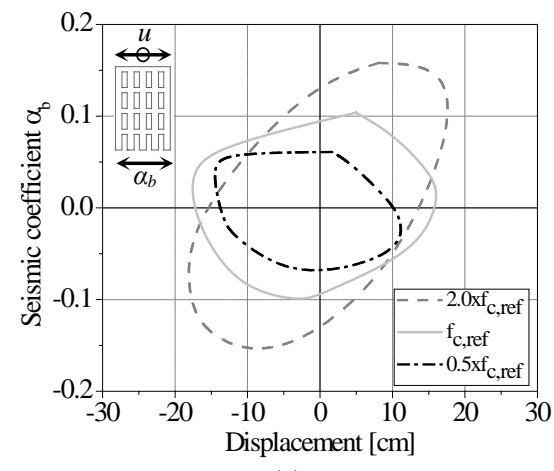

(a)

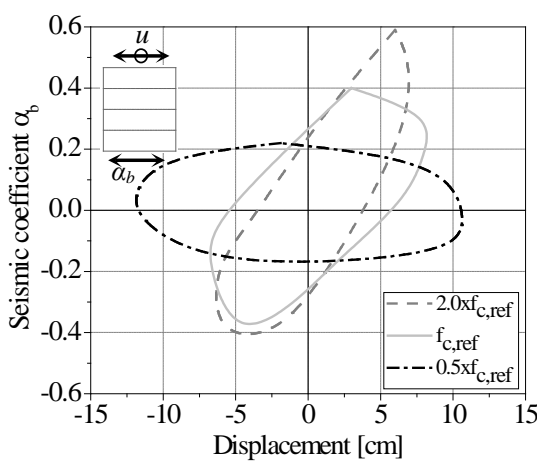

(b)

Fig. 14 Envelope of the response varying the compressive strength in the: (a) transversal direction; (b) longitudinal direction.

The vertical component of the earthquake does not have a significant influence on the response, because the compressive stresses due to the self-weight minimize the effect of the vertical acceleration. Furthermore, the structure is very stiff in the vertical direction and, consequently, presented very small displacements in this di- 
rection. The vertical component of the earthquake is not enough to change significantly the state of stress and, consequently, to reduce its strength capacity. It is noted that the numerical model was prepared according to a macro-modelling strategy, in which the mortar and interfaces unit/mortar are not simulated. In real cases, the vertical component of the earthquake can reduce the normal compressive stress in the mortar and in the interfaces, causing some cracking. This might become particularly relevant in rubble masonry and mortar with low cohesion.

Tables 4 and 5 present the variation of the maximum seismic coefficient and displacement at the top of the structure obtained from the non-linear dynamic parametric analysis for the transversal direction (direction with the lowest strength capacity), where values larger than 20\% are highlighted. It is considered that the analysis is oversensitive to the Young's modulus and the masonry compressive strength.

Table 4 Variation of the response in the transversal direction obtained from the dynamic parametric analysis for the lower limits of the parameters.

\begin{tabular}{|c|c|c|c|c|c|c|c|}
\hline & $\mathbf{0 . 5} \times \boldsymbol{E}_{\text {walls,ref }}$ & $\mathbf{0 . 1} \times \boldsymbol{E}_{\text {floors, ref }}$ & $\mathbf{0 . 5} \mathbf{x} \boldsymbol{f}_{\boldsymbol{c}, \text { ref }}$ & $\mathbf{0 . 5} \mathbf{x} \boldsymbol{G}_{\boldsymbol{c}, \text { ref }}$ & $\mathbf{0 . 5} \mathbf{x} \boldsymbol{f}_{t, \text { ref }}$ & $\mathbf{0 . 5} \mathbf{x} \boldsymbol{G}_{t, \text { ref }}$ & $\zeta=\mathbf{2} \%$ \\
\hline Seismic coefficient & $-10 \%$ & $10 \%$ & $-20 \%$ & $0 \%$ & $-2 \%$ & $10 \%$ & $0 \%$ \\
\hline Displacement & $-7 \%$ & $24 \%$ & $-16 \%$ & $-11 \%$ & $4 \%$ & $-1 \%$ & $0 \%$ \\
\hline
\end{tabular}

Table 5 Variation of the response in the transversal direction obtained from the dynamic parametric analysis for the upper limits of the parameters and earthquake vertical component.

\begin{tabular}{|c|c|c|c|c|c|c|c|c|}
\hline & $\mathbf{2 . 0 \times} \boldsymbol{E}_{\text {walls,ref }}$ & $\mathbf{1 0 \times E _ { \text { floors, ref } }}$ & $\mathbf{2 . 0 \times f _ { c , \text { ref } }}$ & $\mathbf{2 . 0 \times \boldsymbol { G } _ { \boldsymbol { c } , \text { ref } }}$ & $\mathbf{2 . 0 \times f _ { t , \text { ref } }}$ & $\mathbf{2 . 0 \times \boldsymbol { G } _ { t , \text { ref } }}$ & $\boldsymbol{\zeta}=\mathbf{5 \%}$ & $\begin{array}{c}\text { Vertical } \\
\text { earthquake }\end{array}$ \\
\hline Seismic coefficient & $39 \%$ & $20 \%$ & $70 \%$ & $20 \%$ & $20 \%$ & $10 \%$ & $10 \%$ & $10 \%$ \\
\hline Displacement & $-17 \%$ & $-6 \%$ & $3 \%$ & $3 \%$ & $0 \%$ & $-4 \%$ & $-17 \%$ & $-3 \%$ \\
\hline
\end{tabular}

\section{Pushover parametric analysis}

As previously carried out for the non-linear dynamic parametric analysis, a pushover parametric analysis is presented next, considering the same variations for the material parameters. Furthermore, the type of load pattern applied horizontally to the structure was also discussed. A pushover analysis with a horizontal displacement distribution proportional to the shape of the first mode in the applied direction was carried out besides the uniform load distribution (Table 6). Here, the objective is to evaluate the response of the structure under a seismic action based on displacement (modal distribution) with respect to a loading based in force (proportional to the mass). Note that according to [31], a uniform load distribution is recommended for a force based pushover analysis in historical buildings. Next, the most relevant variations of the response are presented. 
Table 6 Parameters considered in the pushver parametric analysis.

\begin{tabular}{|c|c|c|c|}
\hline & Lower value & Reference value & Upper value \\
\hline Young's modulus of the walls & $0.5 \mathrm{x} E_{\text {walls, ref }}$ & $E_{\text {walls,ref }}=1.00 \mathrm{GPa}$ & $2.0 x E_{\text {walls,ref }}$ \\
\hline Young's modulus of the floors & $0.1 \mathrm{x} E_{\text {floors, ref }}$ & $E_{\text {floors, }, \text { ef }}=0.16 \mathrm{GPa}$ & $10 x E_{\text {floors, ref }}$ \\
\hline Compressive strength & $0.5 x f_{c, r e f}$ & $f_{c, r e f}=1.00 \mathrm{MPa}$ & $2.0 \times f_{c, r e f}$ \\
\hline Compressive fracture energy & $0.5 \times G_{c, r e f}$ & $G_{c, \text { ref }}=1.00 \mathrm{~N} / \mathrm{mm}$ & $2.0 \times G_{c, r e f}$ \\
\hline Tensile strength & $0.5 x f_{t, r e f}$ & $f_{t, r e f}=0.10 \mathrm{MPa}$ & $2.0 x f_{t, r e f}$ \\
\hline Tensile fracture energy & $0.5 \times G_{t, r e f}$ & $G_{t, r e f}=0.05 \mathrm{~N} / \mathrm{mm}$ & $2.0 \times G_{t, r e f}$ \\
\hline Load pattern & \multicolumn{3}{|c|}{ Displacement proportional to the shape of the first mode } \\
\hline
\end{tabular}

The parametric analysis confirms that the Young's modulus of the masonry walls, the stiffness of the timber floors and the compressive strength have the highest influence on the strength capacity of the structure. The decrease of the tensile strength causes also a significant decrease of the strength capacity in the longitudinal direction (-20\%). In the pushover analysis in the transversal direction (direction with the lowest strength capacity) the damage is caused by in-plane forces at the façades and is similar to the one obtained from the non-linear dynamic analysis, in which severe damage at the spandrels and piers is found.

In the pushover analysis with varying Young's modulus of the timber floors, the maximum seismic coefficient presents variations of about 12\% (Figure 15). The major differences occur in the pushover analysis in the longitudinal direction, which is more dependent of the stiffness of the timber floors. The numerical model with $10 x E_{\text {floors,ref }}$ presents a response stiffer than the reference model and with a high reduction of the lateral forces after post-peak for low deformation (more brittle behaviour). On the other hand, the response of the numerical model with $0.1 \mathrm{x} E_{\text {floors,ref }}$ presents several loss of stiffness until the maximum seismic coefficient and high deformation (Figure 15b). In the end of the pushover analyses in the longitudinal direction the numerical models with $0.1 \times E_{\text {floors,ref }}$ and $10 x E_{\text {floors,ref }}$ present similar seismic coefficient and significantly different displacements. This is due to the severe damage in the numerical model with $0.1 \mathrm{x} E_{\text {floors,ref, }}$ mainly due to the vertical crack near the corners, which causes the out-of-plane collapse of the façades (Figure 16a). In the numerical model with $10 x E_{\text {floors, ref }}$ collapse occurs due to shear failure of the gable walls (Figure 16b).

Finally, the pushover analysis in which a displacement distribution proportional to the shape of the first mode was applied presents lower strength capacity with respect to the pushover analysis with distribution of forces proportional to mass, and does not provide any improvement in the simulation of the local damage at the piers of the top floor caused by the out-of-plane bending, as observed in the experimental tests. 




(a)

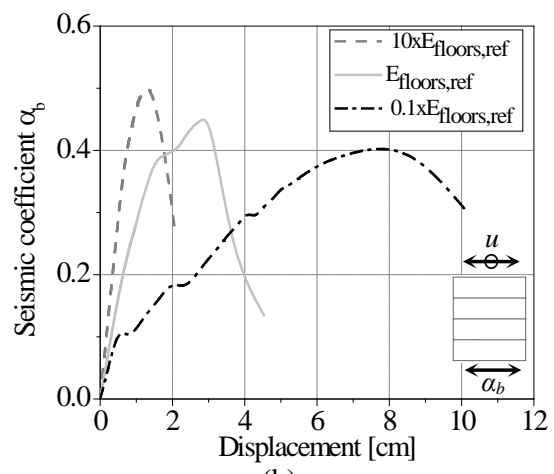

(b)

Fig. 15 Capacity curves varying the Young's modulus of the timber floors in the: (a) transversal direction; (b) longitudinal direction.

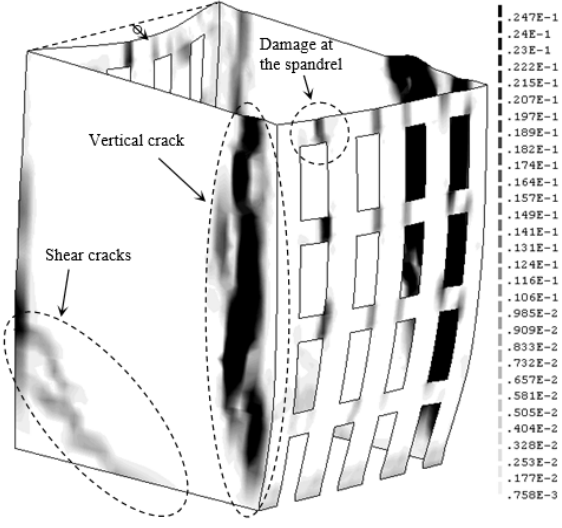

(a)

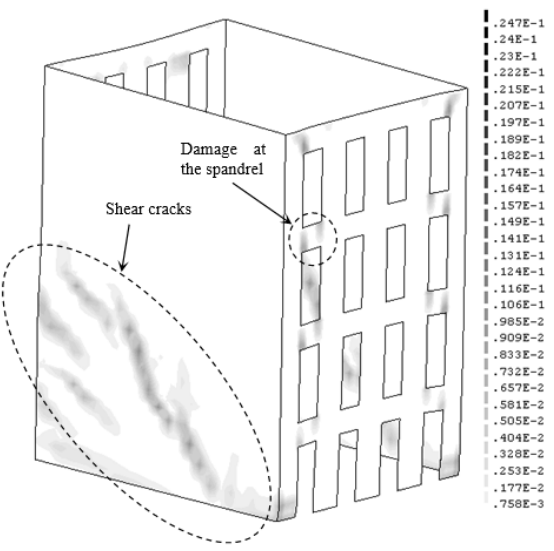

(b)

Fig. 16 Maximum tensile principal strains at the external surface, obtained from the pushover analysis in the longitudinal direction, varying the Young's modulus of the floors:

(a) $0.1 \times E_{\text {floors, ref }}$; (b) $10 x E_{\text {floors, ref. }}$

Tables 7 and 8 present the variations of the maximum seismic coefficient obtained from the pushover parametric analysis for the transversal and longitudinal directions, where values larger than $20 \%$ are highlighted. It is considered that the analysis is oversensitive to the Young's modulus and the masonry compressive strength, which is exactly the same conclusion of the dynamic analysis. Furthermore, the extreme variation found for the compressive strength in the dynamic analysis (up to $70 \%$ of the reference value) was not replicated by the pushover analysis. 
Table 7 Variation of the maximum seismic coefficient obtained from the pushover parametric analysis for the lower limits of the parameters.

\begin{tabular}{|c|c|c|c|c|c|c|}
\hline Direction & $\mathbf{0 . 5} \times \boldsymbol{E}_{\text {walls,ref }}$ & $\mathbf{0 . 1} \mathbf{x} \boldsymbol{E}_{\text {floors,ref }}$ & $\mathbf{0 . 5} \mathbf{x} \boldsymbol{f}_{\boldsymbol{c}, \text { ref }}$ & $\mathbf{0 . 5} \mathbf{x} \boldsymbol{G}_{\boldsymbol{c}, \text { ref }}$ & $\mathbf{0 . 5} \mathbf{x} \boldsymbol{f}_{\boldsymbol{t}, \text { ref }}$ & $\mathbf{0 . 5} \mathbf{x} \boldsymbol{G}_{t, \text { ref }}$ \\
\hline Transversal & $-2 \%$ & $-10 \%$ & $-32 \%$ & $-3 \%$ & $-2 \%$ & $-6 \%$ \\
\hline Longitudinal & $-9 \%$ & $-14 \%$ & $-37 \%$ & $-7 \%$ & $-20 \%$ & $-6 \%$ \\
\hline
\end{tabular}

Table 8 Variation of the maximum seismic coefficient obtained from the pushover parametric analysis for the upper limits of the parameters and pushover analysis with displacement distribution proportional to the shape of the first mode.

\begin{tabular}{|c|c|c|c|c|c|c|c|}
\hline Direction & $2.0 \times E_{\text {walls,ref }}$ & $10 \times E_{\text {floors, ref }}$ & $2.0 \times f_{c, r e f}$ & $2.0 \times G_{c, r e f}$ & $2.0 \times f_{t, r e f}$ & $2.0 \times G_{t, r e f}$ & $1^{\text {st }}$ Mode \\
\hline Transversal & $25 \%$ & $11 \%$ & $34 \%$ & $13 \%$ & $11 \%$ & $8 \%$ & $-12 \%$ \\
\hline Longitudinal & $11 \%$ & $12 \%$ & $8 \%$ & $1 \%$ & $8 \%$ & $11 \%$ & $-27 \%$ \\
\hline
\end{tabular}

\section{Stenghtening of floors}

The in-plane stiffness of the floors has an important role in the global behaviour of existing masonry buildings. The decrease of the Young's modulus of the floors presented significant differences on the crack pattern and on the out-of-plane response of the walls with respect to the reference model. Thus, the strengthening of the stiffness of the floors, in order to guarantee the diaphragm effect with transfer of inertial forces among orthogonal walls, is essential to improve the global behaviour of existing masonry buildings. Here, an ideal condition of a building without floors and two strengthening techniques were evaluated. The building without floors includes the self-weight of the floors and partition walls through concentrated masses applied in the walls at the floors levels. Thus, the total mass is equal to the total mass of the reference model. In the first strengthening technique the in-plane stiffness of the timber floors were increased by doubling its thickness $(7.2 \mathrm{~cm})$. This technique is based on the strengthening of floors with the superposition of and additional layer of wood with the joints in the orthogonal direction to the joints of the original floor. The thickness enlarge of the floors caused an increase of the total mass of about $2 \%$. In the second strengthening technique the timber floors were replaced by reinforced concrete slabs with $20 \mathrm{~cm}$ of thickness. This technique increases significantly the stiffness of the floors. However, the new reinforced concrete slabs increased also the mass at the floor levels (more 23\% with respect to the reference model) and, consequently, the inertial forces. It is noted that booth strengthening techniques of the floors implies an appropriated connections between floors and masonry walls.

Non-linear dynamic analysis with time integration were carried out, aiming at comparing the seismic performance of the building for the different conditions. In these analyses the Earthquake $100 \%$, which corresponds to the code amplitude $\left(P G A=1.5 \mathrm{~m} / \mathrm{s}^{2}\right)$, was applied.

Figure 17 presents the maximum tensile principal strains for the three conditions. It is observed that the models present different crack patterns. The model 
without floors presents a vertical crack at the middle of the gable walls and severe damage at the top of the façades, which is typical of structures without box behaviour. The model with strengthening of the timber floors by doubling the thickness of the floors do not presents vertical cracks in the gable walls and damage concentrates at the first floor, mainly due to the in-plane behaviour. The model with reinforced concrete slabs presents severe damage at lower two floors, due high inertial forces caused by the masse of the reinforced concrete slabs. Figure 18 presents the maximum out-of-plane at the middle of façade for the Earthquake $100 \%$. The maximum displacement of the reference model is equal $2.1 \mathrm{~cm}$ and occurs at the third floor. The model without floors presents the highest displacement at the top floor $(6.4 \mathrm{~cm})$. The model with reinforced concrete slabs presents displacements higher than the reference model, in which an increasing of out-of-plane displacement at the third floor of about $72 \%$ with respect to the reference model is highlighted. The model with increasing of the thickness of the floors presents the lowest out-of-plane. This model presents a reduction of out-of-plane displacement at the third floor of about $27 \%$ with respect to the reference model. Thus, strengthening of the floors by doubling its thickness is the technique most appropriate for improving the global behaviour of the building, increasing the in-plane stiffness of the floors without increased significantly the inertial forces at floor levels.

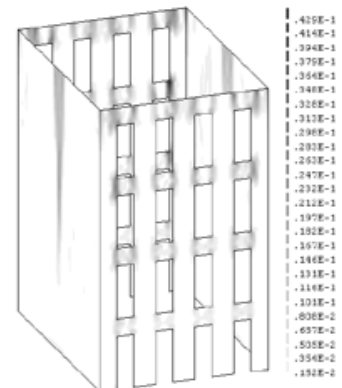

(a)

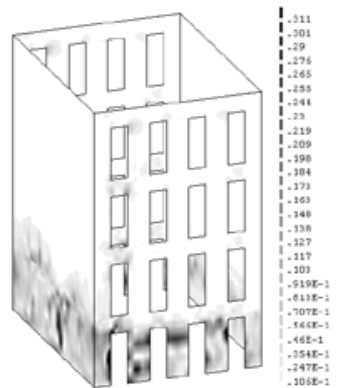

(b)

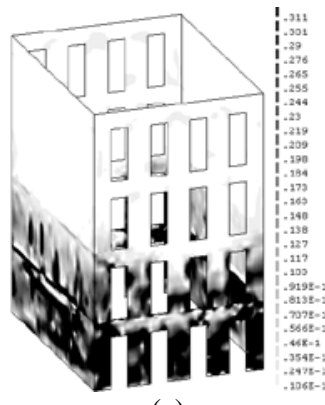

(c)

Fig. 17 Maximum tensile principal strains at the external surface, obtained from the dynamic analysis, for the: (a) model without floors; (b) model with strengthening of the timber floors by doubling the thickness of the floors; (c) model with reinforced concrete slabs.



Fig. 18 Maximum out-of-plane displacement at the midle of the façade. 


\section{Conclusions}

A parametric analysis using two techniques of structural modelling was carried out, namely: (a) non-linear dynamic analysis with time integration; (b) pushover analysis with a distribution of forces proportional to the mass. The objective was to evaluate the variation of the response taking into account the deviations in the main features of an existing masonry building typology of the housing stock of Portugal with reasonable height (4 to 6 storeys) - gaioleiro buildings. The results were mainly compared in terms of maximum load capacity and collapse mechanisms. The Young's modulus of the masonry walls, Young's modulus of the timber floors, the compressive and tensile non-linear properties (strength and fracture energy) were the parameters considered in both parametric analyses. The influence of viscous damping and the vertical component of the earthquake was also considered in the non-linear dynamic analysis. Finally, a pushover analysis proportional to the modal displacement of the first mode in each direction was also carried out.

The non-linear dynamic analysis with time integration of the reference model with the Earthquake $100 \%\left(P G A=1.5 \mathrm{~m} / \mathrm{s}^{2}\right)$ shows that the structure reaches its strength capacity in the transversal direction. A seismic coefficient equal to 0.10 was obtained for this direction, which is in agreement with the results obtained from the pushover analysis in the transversal direction. However, in the Earthquake $100 \%$ the deformation is moderate and the seismic amplitude was increased three times (Earthquake 300\%) for the parametric analysis through non-linear dynamic analysis, aiming at exploring the deformation capacity of the structure and at clearly identifying the collapse mechanisms. In the analysis with the Earthquake $300 \%$ the structure presents serious damage at the spandrels due to diagonal cracking and at the piers of the top floors due to the in-plane rocking and out-ofplane bending, indicating that collapse has been found. Furthermore, the piers of the first floor also present severe damage associated to the failure of the spandrels due to the in-plane forces. The gable walls presents shear cracks, a vertical crack at the top and local damage at the connections between masonry wall and timber floor of the first floor. The pushover analysis in the transversal direction is able to simulate only the damage at the façades caused by in-plane forces, namely the damage at the spandrels and at the piers. The capacity and failure mode obtained from pushover analysis in the longitudinal direction are not in agreement with the results of the dynamic analysis and with several analyses made for masonry buildings without box behaviour.

The parametric analysis shows that, for this building typology, the results are oversensitive to the Young's modulus and compressive strength of the masonry walls for either dynamic time integration or pushover analyses. The Young's modulus of the timber floors also has some influence in the response, either in strength and collapse mechanism. The vertical component of the earthquake does not have any influence on the response of the numerical model, which is due to the 
high compressive stresses caused by self-weight and high stiffness in the vertical direction. The pushover analysis with a displacement distribution proportional to the shape of the first mode presents a lower strength capacity with respect to the pushover analysis with distribution of forces proportional to the mass, and does not provide a better agreement with the failure mode from the dynamic analysis and the experimental results.

Finally, and taking into account that the stiffness floors has an important role in the seismic performance of masonry structures, a study on the strengthening of floors was carried out. Two strengthening techniques were considered, namely: (a) strengthening of the original timber floors by doubling its thickness; (b) replacement of the original floors by reinforced concrete floors. The results of the nonlinear dynamic analysis with time integration showed that the increase of the thickness of the timber floors is the most appropriated strengthening techniques for improving the global seismic performance of the structure. This strengthening technique increases the stiffness of the floors with a very low increase of the total mass at the floors levels and, consequently, of the inertial forces. As final consequence, the model presents a significant reduction of the out-of-plane displacements of the masonry walls. It is noted that an appropriate connection between floors and masonry walls is needed.

\section{References}

[1] Paulay T, Priestley M. Seismic design of reinforced concrete and masonry buildings. John Wiley \& Sons Inc, 1992.

[2] Toumbakari E. Lime-pozzolan-cement grouts and their structural effects on composite masonry walls. PhD Thesis, Katholieke Universiteit Leuven, Belgium, 2002.

[3] Valluzi M, Porto F, Modena C. Behaviour and modelling of strengthened three-leaf stone masonry walls. Materials and Structures 2004; 37(3):184-192. (doi:10.1007/BF02481618)

[4] Lourenço PB. Computational strategies for masonry structures. PhD Thesis, Delft University of Technology, Netherlands, 1996.

[5] Pinho F. Walls from existing Portuguese buildings. "Edifícios", No8, National Laboratory for Civil Engineering, Lisbon, Portugal, 2000. (in Portuguese)

[6] Tomaževič M. Earthquake-resistance design of masonry buildings. Series on Innovation in Structures and Construction, Vol. 1, 1999. Imperial College Press.

[7] EN 1998-1. Eurocode 8: Design of structures for earthquake resistance - General rules, seismic actions and rules for building. European Committee for Standardization, 2004.

[8] FEMA 440. Improvement of nonlinear static seismic analysis procedures. Applied Technology Council (ATC-55 Project), Department of Homeland Security, Federal Emergency Management Agency, Washington D.C, 2005.

[9] OPCM 3274. First elements on general criteria for seismic classification of the national territory and technical standards for construction in seismic areas. Ordinance of the President of the Council of Ministers, 2003. (in Italian)

[10] Bothara J, Brzev S. A tutorial: Improving the seismic performance of stone masonry buildings. Earthquake Engineering Research Institute, $1^{\text {st }}$ edition , 2011. (ISBN: 978-1932884-48-7) 
[11] Carocci C. Guidelines for the safety and preservation of historical centres in seismic areas. Historical Constructions: Possibilities of numerical and experimental techniques, Guimarães, Portugal, 145-166, 2001.

[12] Magenes G, Calvi G. In-plane seismic response of brick masonry walls. Earthquake Engineering and Structural Dynamics 1997; 26(11):1091-1112. (doi:10.1002/(SICI)10969845(199711)26:11<1091::AIDEQE693>3.0.CO;2-6)

[13] Bosiljkov V, Page A, Bokan-Bosiljkov V, Žarnić R. Performance based studies of in-plane loaded unreinforced masonry walls. Masonry International 2003; 16:39-50. (http://hdl.handle.net/1959.13/27605)

[14] Yi T. Experimental investigations and numerical simulation of an unreinforced masonry structure with flexible diaphragms. PhD Thesis, Georgia Institute of Technology, 2004.

[15] Cattari S, Lagomarsino S. A strength criterion for flexural behaviour of spandrels in unreinforced masonry walls. The $14^{\text {th }}$ World Conference on Earthquake Engineering, Beijing, China, 2008.

[16] Beyer K, Mangalathu, S. Review of strength models for masonry spandrels. Bulletin of Earthquake Engineering; 2013; 11(2):521-542. (doi:10.1007/s10518-012-9394-3)

[17] Magenes G, Bolognini D, Braggio C. Simplified methods for non-linear seismic of masonry buildings. National Group for Earthquakes Protection (GNDT), 2000. (in Italian)

[18] FEMA 306. Evaluation of earthquake damaged concrete and masonry wall buildings. Applied Technology Council (ATC-43 Project). The Partnership for Response and Recovery, Federal Emergency Management Agency, Washington D.C., 1998.

[19] Candeias P. Seismic vulnerability assessment of ancient buildings. PhD Thesis. University of Minho, Portugal, 2008. (http://hdl.handle.net/1822/9057) (in Portuguese)

[20] Penna A. Vulnerability assessment of masonry structures using experimental data and simplified models. Short course and post-earthquake buildings safety and damage assessment, Eucentre, Pavia, 2008.

[21] Dazio A, Beyer K. Seismic behaviour of different types of masonry spandrels. $14^{\text {th }}$ European Conference on Earthquake Engineering. Ohrid, Republic of Macedonia, paper 468, 2010.

[22] Lagomarsino S. Seismic performance of masonry buildings after the 2009 L'Aquila earthquake. Learning from the past to protect the future. EERI Annual Meeting \& National Earthquake Conference, United States of America, 2012.

[23] Ingham J, Biggs D, Moon L. (2011). How did unreinforced masonry buildings perform in the February 2011 Christchurch earthquake?. The Structural Engineer 2012; 89(6):14-18.

[24] Brignola A, Podestá S, Pampanin S. In-plane stiffness of wooden floor. New Zealand Society for Earthquake Engineering Conference, paper number 49, 2008.

[25] Bruneau M. Seismic performance of unreinforced masonry buildings - a state-of-art report. Canadian Journal of Civil Engineering 1994; 21(3):512-539. (doi: 10.1139/194-054)

[26] Bruneau M. State-of-art report on seismic performance of unreinforced masonry buildings. Journal of Structural Engineering 1994; 120(1):230-251. (doi:http://dx.doi.org/10.1061/(ASCE)0733-9445(1994)120:1(230))

[27] Paquette J, Bruneau M. Pseudo-dynamic testing of unreinforced masonry building with flexible diaphragm and comparison with existing procedures. Construction and Building Materials 2006; 20(4): 220-228. (doi:10.1016/j.conbuildmat.2005.08.025)

[28] Tomaževič M, Lutman P, Weiss P. Seismic upgrading of old brick-masonry urban houses: Tying of walls with steel ties. Earthquake Spectra 1996; 12(3):599-622.

[29] Ewing R, Johnson A, Kariotis J. Methodology for mitigation of seismic hazards in existing unreinforced masonry buildings (ABK methodology): diaphragm testing. ABK-TR-03, ABK, El Segundo, California, 1981.

[30] SEAOC. Earthquake hazard mitigation of unreinforced pre-1933 masonry buildings: Construction notes for contractors, building officials, owners/developers, architects, engineers. Structural Engineers Association of Southern California, 1986. 
[31] Lourenço PB, Mendes N, Ramos LF, Oliveira DV. Analysis of masonry structures without box behavior. International Journal of Architectural Heritage 2011; 5, 4: 369-382. (doi:10.1080/15583058.2010.528824)

[32] Costa AA, Arêde A, Campos-Costa A, Penna A, Costa A. Out-of-plane behaviour of a full scale stone masonry façade. Part 2: shaking table tests. Earthquake Engineering and Structural Dynamics 2013; 42:2097-2111. (doi: 10.1002/eqe.2314)

[33] Pere R, Cervera M, Gariup G, Pela L. Structural analysis of masonry historical constructions. Classical and advanced approaches. Archives of Computational Methods in Engineering 2010; 17(3):299-325. (doi:10.1007/s11831-010-9046-1)

[34] Appleton J. Rehabilitation of "gaioleiros" buildings - a block in Lisbon. Orion edition, 2005. (ISBN: 9728620055) (in Portuguese)

[35] Mendes N, Lourenço PB, Campos-Costa A. Shaking table testing of an existing building: assessment and improvement of the seismic performance. Earthquake Engineering \& Structural Dynamics 2014; 43: 247-266. (doi:10.1002/eqe.2342).

[36] TNO. DIsplacement method ANAlyser. User's Manual, Release 9.4, Netherlands; 2009.

[37] Mindlin RD. Influence of rotary inertia and shear on flexural motions of isotropic elastic plates. Journal of Applied Mechanics 1995; 18:31-38.

[38] Reissner E. The effect of transverse shear deformation on the bending of elastic plates. Journal of Applied Mechanics 1945; 12:68 -77.

[39] Chopra A. Dynamics of Structures: Theory and applications to earthquake engineering. $3^{\text {rd }}$ ed. Prentice Hall, 2001.

[40] Gulkan P, Aschheim M, Spence R. Reinforced concrete frame buildings with masonry infills. World Housing Encyclopedia, Housing report: 64, 2002. (Available fromwww.world-housing.net)

[41] Viviane W. Mitigation of pounding between adjacent buildings in earthquake situations. LESSLOSS final workshop, Sub-project 7 - Vulnerability reduction in structures, 2007.

[42] Ramos LF, Lourenço PB. Modeling and vulnerability of historical city centers in seismic areas: a case study in Lisbon. Engineering Structures 2004; 26:1295-1310. (doi:10.1016/j.engstruct.2004.04.008)

[43] Carvalho A. Stochastic modelling of the seismic action in Mainland Portugal. PhD Thesis, Technical University of Lisbon, Portugal, 2007. (in Portuguese)

[44] PIET-70. Masonry works. Prescriptions from Instituto Eduardo Torroja. Higher Council of Scientific Researches, CSIC, Madrid, 1971.

[45] NTC08. Technical Standards for Construction. Italian Ministry of Infrastructures and Transportation. G.U.n.29-S.O.n.30, 2008. (in Italian)

[46] Cóias V. Structural rehabilitation of existing buildings. Argumentum, 2007. (ISBN: 978972-8479-40-9) (in Portuguese) 